\title{
ESTIMATION OF OCEAN CURRENT VELOCITY IN COASTAL AREA USING RADARSAT-1 SAR IMAGES AND HF-RADAR DATA
}

\author{
Moon-Kyung Kang ${ }^{1}$, Hoonyol Lee ${ }^{2}$, Chan-Su Yang ${ }^{3}$, Wang-Jung Yoon ${ }^{4}$ \\ ${ }^{1}$ Ocean Satellite Research Group, Korea Ocean Research \& Development Institute (KORDI), \\ Ansan, Republic of Korea, mkkang@kordi.re.kr \\ ${ }^{2}$ Department of Geophysics, Kangwon National University, \\ Chuncheon, Republic of Korea, hoonyol@kangwon.ac.kr \\ ${ }^{3}$ Ocean Satellite Research Group, Korea Ocean Research \& Development Institute (KORDI), \\ Ansan, Republic of Korea, yangcs@kordi.re.kr \\ ${ }^{4}$ Department of Geosystem Engineering, Chonnam National University, \\ Gwangju, Republic of Korea, wjyoon@chonnam.ac.kr
}

\begin{abstract}
This paper presents the results of the surface current velocity estimation using 6 Radarsat-1 SAR images and high frequency (HF) radar data acquired in west coastal area near Incheon, Korea. We extracted the surface velocity from SAR images based on the Doppler shift approach in which the azimuth frequency shift is related to the motion of surface target in the radar direction. The extracted SAR current velocities were statistically compared with the current velocities from the HF-radar data. The corrected SAR current velocity inherits the average of HF-radar while maintaining high-resolution mature of the original SAR data.
\end{abstract}

Index Terms-Doppler shift, ocean current velocity, SAR, HF-radar

\section{INTRODUCTION}

Unlike the target on the land, the radar scattering mechanism over the ocean must be taken into account the sea surface motion as well as its roughness and dielectric constant. Moving targets over the ocean cause the Doppler shift of the backscattered radar signal, proportional to the target's line-of-sight velocity. Ocean surface current velocity can be evaluated by estimating the Doppler frequency of the SAR data. The Doppler shift can be measured by estimating the difference of the Doppler centroid obtained from the SAR data and the nominal Doppler centroid calculated by using the trajectory parameters of satellite orbit.

The purpose of this study is 1) the estimation of ocean current velocity from SAR images using the Doppler shift method and 2) the evaluation and correction of the results by comparing them with HF-radar data.

\section{METHODOLOGY}

The study area is located near Incheon in the west coast of the Korean Peninsula (Fig. 1) where the tidal current speed is much higher than that of the eastern or southern coast of Korea.

Total 6 Radarsat-1 SAR images were used in this study that were acquired in May 6 and 30, July 17, August 10, September 27, and October 21, 2003, respectively. The Radarsat-1 SAR operated at C-band $(5.3 \mathrm{GHz})$ in $\mathrm{HH}$ polarization, and the images used in this study were all in ascending orbit, standard mode 5 with approximately $39^{\circ}$ of incidence angle, as listed in Table 1.

The HF-radar data used in this work were measured by National Oceanographic Research Institute (NORI) of Korea at the same time of SAR data acquisition and also in the West Sea between $37^{\circ} 17^{\prime} 34^{\prime \prime}$ to $37^{\circ} 28^{\prime} 7^{\prime \prime} \mathrm{N}$ and $126^{\circ} 25^{\prime} 7^{\prime \prime}$ to $126^{\circ} 36^{\prime} 52^{\prime \prime} \mathrm{E}$. It gives the current velocity data in east and north direction.

For the estimation of the surface velocity from SAR images, we used the SAR Ocean Processor (SOP) developed by Kangwon National University, Korea. The aims of the SOP are the extraction of ocean wind, wave, and current parameters from SAR images [8]. The SOP which is an open software (http://sar.kangwon.ac.kr/sop.htm) works at cygwin (www.cygwin.com) environment and the output files of the SOP are produced separately for the wind, wave, and current information. The SOP implemented the existing algorithms such as the CMOD4 [1],[2], CMOD-IFR2 [6] models, and a polarization ratio conversion [7] for the retrieval of wind speed, the wave-SAR transforms and inter- 
look cross-spectra [5] for the extraction of wavelength and propagation direction of wave, and the Doppler shift approach [3] for the estimation of the surface current velocity. Only the surface current velocity is extracted by the SOP and evaluated in this paper as it is a dominant oceanic phenomenon in this study area driven by the strong tidal current.

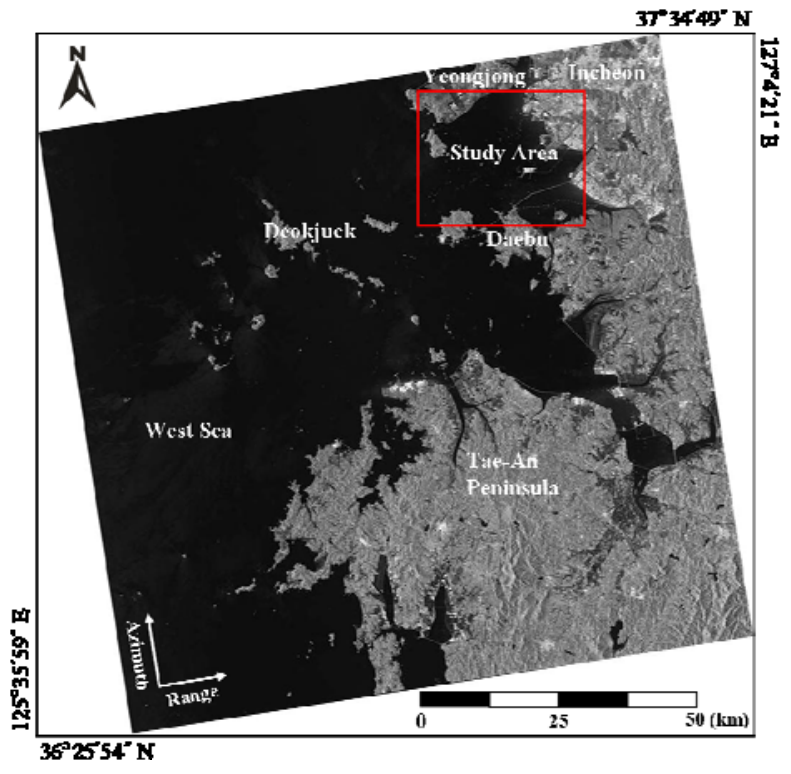

Fig. 1. Study area depicted in a Radarsat-1 SAR image.

Table 1. The used Radarsat-1 SAR images.

\begin{tabular}{|c|c|c|c|}
\hline $\begin{array}{c}\text { Date } \\
\text { (dd/mm/yyyy) }\end{array}$ & $\begin{array}{c}\text { Local Time } \\
\text { (hh:mm:ss) }\end{array}$ & $\begin{array}{c}\text { Scene Center } \\
\text { (deg) }\end{array}$ & $\begin{array}{c}\text { Incidence } \\
\text { Angle (deg) }\end{array}$ \\
\hline $06 / 05 / 2003$ & $18: 33: 25$ & $\begin{array}{c}37.013909 \mathrm{~N}, \\
126.365369 \mathrm{E}\end{array}$ & 39.172 \\
\hline $30 / 05 / 2003$ & $18: 33: 22$ & $\begin{array}{c}37.038920 \mathrm{~N}, \\
126.210235 \mathrm{E}\end{array}$ & 39.173 \\
\hline $17 / 07 / 2003$ & $18: 33: 17$ & $\begin{array}{c}37.020402 \mathrm{~N}, \\
126.369676 \mathrm{E}\end{array}$ & 39.164 \\
\hline $10 / 08 / 2003$ & $18: 33: 14$ & $\begin{array}{l}37.020693 \mathrm{~N}, \\
126.372177 \mathrm{E}\end{array}$ & 39.163 \\
\hline $27 / 09 / 2003$ & $18: 33: 13$ & $\begin{array}{l}37.015542 \mathrm{~N}, \\
126.360884 \mathrm{E}\end{array}$ & 39.153 \\
\hline $21 / 10 / 2003$ & $18: 32: 58$ & $\begin{array}{l}36.994699 \mathrm{~N}, \\
126.365933 \mathrm{E}\end{array}$ & 39.157 \\
\hline
\end{tabular}

The overall procedure for the estimation of the surface current velocity from Radarsat-1 SAR images and HF-radar data is outlined in Fig. 2.

The current velocity of HF-radar was observed in two directions: eastward $\left(\mathrm{u}_{\mathrm{E}}\right)$ and northern $\left(\mathrm{u}_{\mathrm{N}}\right)$ direction. The measured HF-radar data were in text format files that should be changed to grid map for subsequent image processing. As the SAR current velocity extracted from the SOP is in range direction only, the HF-radar current velocity should be rotated to range and azimuth directions for comparison.
The georeferenced map of the SAR and HF-radar current velocities were overlaid and masked out so that the area includes the coastal ocean surface only and keeps a good distance from the lands nearby. The velocities from HFradar in range direction $\left(\mathrm{u}_{\mathrm{rg}}\right)$ and SAR image data $\left(\mathrm{v}_{\mathrm{sar}}\right)$ were compared and analyzed by a simple statistical method such as averages, standard deviations, and root mean square (RMS) errors. Assuming the HF-radar data as a reference, the SAR velocity was corrected $\left(\mathrm{v}_{\text {sarc }}\right)$ accordingly.

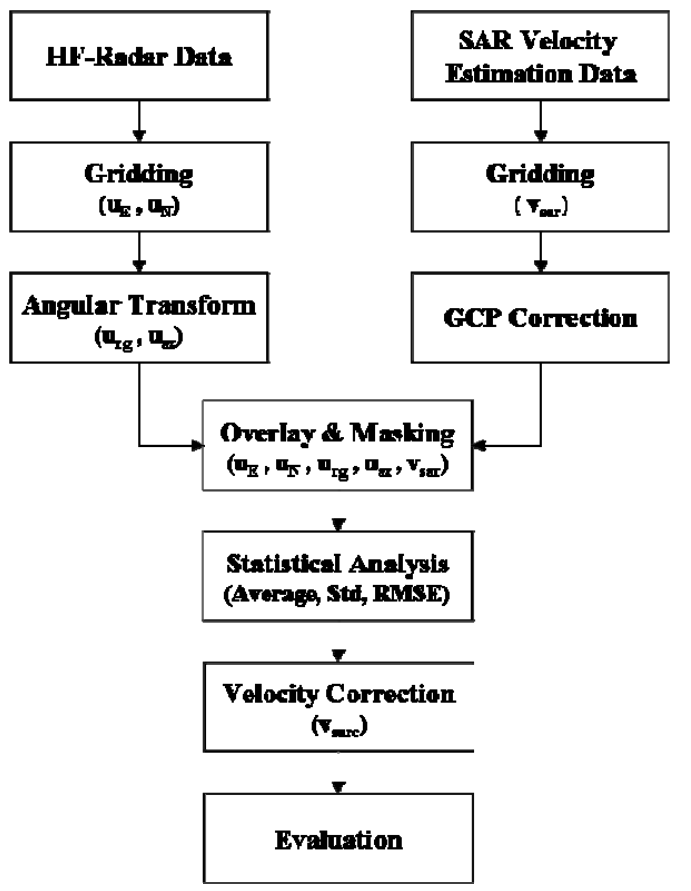

Fig. 2. The overall procedure for estimation of the surface current velocity from SAR and HF-radar data.

\section{RESULTS}

\subsection{Optimization of SOP parameters}

The major input parameters of the SOP for extracting surface current velocity are nptyc for 1D azimuth FFT size, $d c \_x s t e p$ and dc_ystep for current estimation steps, $d c \_a v x$ and $d c \_a v y$ for averaging factor during Doppler center estimation (all in pixel dimension), and vel_scale for velocity vector scale during display (pixel/sec). The nptyc, $d c \_a v x$, and dc_avy have direct influenced on the quality of the surface velocity measurement, which have to be chosen carefully by a certain optimization procedure, while the $d c \_x s t e p, d c \_y s t e p$, and vel_scale parameters give variety in vector display.

Firstly, the parameter optimization for the SOP processing has been performed based on the statistical test on the results from various parameter sets. The results then compared with the HF-radar data and then a correction 
procedure has been implemented to complement the possible errors in the nominal Doppler centroid during SAR focusing. The result with varying averaging window size of $d c \_a v x$ and dc_avy indicates that the large size of the averaging window during the Doppler centroid estimation is necessary to overcome the noise effect of the azimuthfrequency data.

According to SAR principle, the radar beam shape that has the maximum amplitude in the center and degrades along the azimuth direction in a bell-shaped style is visible in an image in range-compressed time and azimuth-frequency domain. By finding a frequency value that gives the maximum amplitude, one can estimate the Doppler centroid and thus the Doppler shift from the nominal Doppler centroid calculated from the satellite's state vectors.

The standard deviation values were generally high when a relatively small averaging window is used for Doppler estimation procedure. This is because of the noisy nature of the azimuth-frequency data that makes the estimation process to easily fall into a local minimum. This localminimum problem during the estimation process can be overcome by enlarging the size of the average window thus to smooth the data field. By doing so, the Doppler centroid can be effectively detected by choosing the frequency value that gives the maximum amplitude out of the typically bellshaped beam model in the azimuth-frequency domain at the expense of resolution. Therefore, the averaging window is a trade off between the estimation accuracy of Doppler centroid and the resolution.

As the tidal current velocity is relatively homogeneous in the study area, it is also expected that the standard deviation of the current velocity should have a small value, and less sensitive to the averaging window size. Therefore, we determined the optimal size of the averaging window by the value that the standard deviation becomes stabilized. From the analysis of the statistical distribution, we selected the optimal averaging window with $d c \_a v x$ and $d c \_a v y$ of 21 by 81 , respectively, and used it for the 6 Radarsat- 1 SAR images. The spatial resolution of the current estimation corresponds to approximately $300 \mathrm{~m} \times 300 \mathrm{~m}$ in this case.

\subsection{Comparison between the SAR and HF-radar current velocities}

Table 2 lists the statistical values of the SAR and HF-radar current velocities such as averages, standard deviations and RMS errors. The sign of averages is positive $(+)$ for flood tide and negative (-) for ebb tide. Fig. 3 exhibits the image sets of the SAR current velocity (first column) and the HFradar current velocity (second column). The flood tide is in yellow color and the ebb tide appears cyan.

The average values of SAR current velocities show a considerable difference when compared with the corresponding HF-radar current velocities. The gap was very high especially on May 30, 2003, where the SAR current velocity indicated unusually high flood tide which is about $+2 \mathrm{~m} / \mathrm{s}$ while the HF-radar current velocity indicates ebb tide. It is evident that there exists a big difference in average values between the SAR and HF-radar data that contributes a lot to the RMS errors while the standard deviation is relatively small. It is postulated that a constant difference in averages of the SAR and HF-radar current velocities can be produced when there is uncertainty in the nominal Doppler centroid estimation during the SAR focusing. The nominal Doppler centroid is calculated from the satellite's state vectors such as the position and velocity vectors with time, which is generally acceptable for general SAR focusing processing [4] but not for the purpose of the velocity estimation causing significant errors. Therefore, we tried to correct the current velocity anomaly of constant type caused by the uncertainty of the nominal Doppler centroid, by using the difference of averages between the SAR and HF-radar current velocities.

\subsection{Correction of the SAR current velocity}

To compensate for the possible errors caused by the nominal Doppler centroid, the difference of averages between the current velocities from SAR and HF-radar was subtracted from the SAR current velocity as:

$$
v_{\text {sarc }}=v_{\text {sar }}-\left(\bar{v}_{\text {sar }}-\bar{u}_{r g}\right)
$$

The images of the corrected SAR current velocity $\left(\mathrm{v}_{\text {sarc }}\right)$ are shown in the $3^{\text {rd }}$ column of Fig. 3 and also the statistics in Table 2. After the correction, the SAR current velocity images ( $3^{\text {rd }}$ columns) are much similar to the HF-radar current images ( $2^{\text {nd }}$ column). There is also a significant improvement in the difference images before ( $4^{\text {th }}$ column) and after the correction ( $5^{\text {th }}$ column). In case of the difference images, red color appear when the SAR velocity is higher than the current velocity of HF-radar and the blue color is for the opposite. From this result we confirmed that the nominal Doppler centroid anomaly during SAR focusing processing can be corrected by using the reference data such as the HF-radar current velocity data.

Table 2 shows that the corrected SAR current velocity ( $\left.\mathrm{v}_{\text {sarc }}\right)$ inherits the average of the HF-radar current velocity $\left(\mathrm{u}_{\mathrm{rg}}\right)$ and the standard deviation of the SAR current velocity before correction $\left(\mathrm{v}_{\mathrm{sar}}\right)$. This means that a constant error in the nominal Doppler centroid has been corrected by the HFradar data while the advantage of higher resolution of the SAR current velocity has been maintained.

\section{CONCLUSIONS}

This study presented the results of estimating the ocean surface current in West Sea near Incheon of the Korean Peninsula by using Radarsat-1 SAR images and HF-radar data. The retrieval of current velocity from SAR images was processed by the SOP program based on the Doppler shift approach. The extracted SAR current velocity was 
compared with the HF-radar current velocity by statistical method such as averages, standard deviations, and RMS errors. We concluded that 1 ) the problem related to the unreliable nominal Doppler centroid estimation during the SAR focusing can be corrected by a reference data such as the HF-radar data; 2) the corrected SAR current velocity has the average of HF-radar data while maintaining the advantage of high-resolution SAR.

\section{ACKNOWLEDGEMENTS}

This work was supported by the Korea Research Foundation Grant funded by the Korean Government (MOEHRD) (KRF-2006-351-D00043).

\section{REFERENCES}

[1] A. Stoffelen and D. Anderson, "Scatterometer Data Interpretation: Estimation and Validation of the Transfer Function CMOD4," J. of Geophysical Research, Vol. 102, No. C3, pp. 5767-5780, 1997a.

[2] A. Stoffelen and D. Anderson, "Scatterometer Data Interpretation: Measurement Space and Inversion," J. of Atmospheric and Oceanic Technology, Vol. 14, pp. 1298-1313, 1997b.

[3] B. Chapron, C. Fabrice, and A. Fabrice, "Direct Measurments of Ocean Surface Velocity from Space: Interpretation and Validation,” J. of Geophysical Research, Vol. 110, pp. 1-17, 2005. [4] Curlander, J. and R. McDonough, Synthetic Aperture Radar: Systems and Signal Processing, John Wiley \& Sons, Inc., New York, 1991.

[5] G. Engen and H. Johnsen, "SAR-Ocean Wave Inversion Using Image Cross Spectra," IEEE Transaction on Antennas and Propagation, Vol. 33, No. 4, pp. 1047-1056, 1995.

[6] IFREMER-CERSAR: Off-Line Wind Scatterometer ERS Products: User Manual, Technical Report C2-MUT-W-010IF, IFREMER-CERSAR, 1999.

[7] J. Horstmann, W. Koch, S. Lehner, and R. Tonboe, "Wind Retrieval over the Ocean using Synthetic Aperture Radar with Cband HH Polarization," IEEE Transaction on Geoscience and Remote Sensing, Vol. 38, No. 5, pp. 2122-2131, 2000.
[8] M. -K. Kang, H. Lee, M. Lee, Y. -W. Park, and W. -J. Yoon, "The Extraction of Ocean Wind, Wave, and Current Parameters Using SAR Imagery,” Proceeding of IGARSS 2007, Barcelona, Spain, pp. 507-510, 2007.

(a)

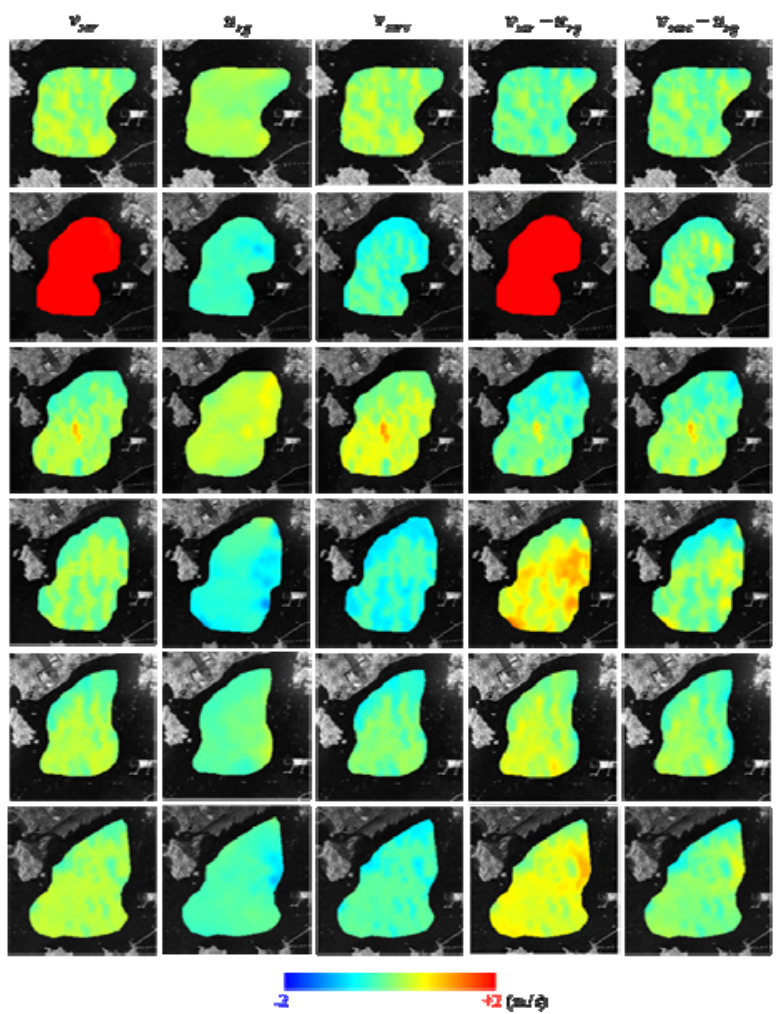

Fig. 3. The ocean current velocity maps in range direction $(\mathrm{m} / \mathrm{s})$ : The acquisition dates of the Radarsat-1 SAR images are (a) May 6, (b) May 30, (c) July 17, (d) August 10, (e) September 27, and (f) October 21,2003 . The $1^{\text {st }}$ column is the SAR current velocity $\left(\mathrm{v}_{\text {sar }}\right)$ and the $2^{\text {nd }}$ is the HF-radar current velocity $\left(\mathrm{u}_{\mathrm{rg}}\right)$. The $3^{\text {rd }}$ column is the corrected SAR current velocity $\left(\mathrm{v}_{\text {sarc }}\right)$. The $4^{\text {th }}$ and the $5^{\text {th }}$ columns are $\mathrm{v}_{\mathrm{sar}}-\mathrm{u}_{\mathrm{rg}}$ and $\mathrm{v}_{\mathrm{sarc}}-\mathrm{u}_{\mathrm{rg}}$.

Table 2. Statistical analysis of the current velocity from SAR and HF-radar.

\begin{tabular}{|c|c|c|c|c|c|c|c|c|c|}
\hline \multirow{2}{*}{$\begin{array}{c}\text { Date } \\
\text { (dd/mm/yyyy) }\end{array}$} & \multicolumn{2}{|c|}{$\mathrm{V}_{\mathrm{sar}}$} & \multicolumn{2}{|c|}{$\mathrm{u}_{\mathrm{rg}}$} & \multicolumn{3}{|c|}{$\mathrm{v}_{\mathrm{sar}}-\mathrm{u}_{\mathrm{rg}}$} & \multicolumn{2}{|c|}{$\mathrm{v}_{\text {sarc }}$} \\
\hline & Avg. & Std & Avg. & Std & Avg. & Std & RMSE & Avg. & Std \\
\hline $06 / 05 / 2003$ & 0.08 & 0.18 & 0.18 & 0.11 & -0.10 & 0.17 & 0.20 & 0.18 & 0.18 \\
\hline $30 / 05 / 2003$ & 2.27 & 0.21 & -0.36 & 0.10 & 2.63 & 0.23 & 2.64 & -0.36 & 0.21 \\
\hline $17 / 07 / 2003$ & 0.11 & 0.25 & 0.33 & 0.13 & -0.22 & 0.27 & 0.35 & 0.33 & 0.25 \\
\hline $10 / 08 / 2003$ & 0.07 & 0.21 & -0.48 & 0.19 & 0.55 & 0.33 & 0.64 & -0.48 & 0.21 \\
\hline $27 / 09 / 2003$ & 0.12 & 0.23 & -0.13 & 0.14 & 0.25 & 0.23 & 0.34 & -0.13 & 0.23 \\
\hline $21 / 10 / 2003$ & 0.22 & 0.16 & -0.29 & 0.14 & 0.51 & 0.21 & 0.55 & -0.29 & 0.16 \\
\hline
\end{tabular}

